\title{
Differentiation of wines with the use of combined data of UV-visible spectra and color characteristics
}

\author{
Ilknur Sen, Figen Tokatli * \\ Izmir Institute of Technology, Department of Food Engineering, Urla-Izmir TR35430, Turkey
}

\section{A R T I C L E I N F O}

\section{Article history:}

Received 17 March 2015

Received in revised form 23 September 2015

Accepted 24 September 2015

Available online 23 October 2015

\section{Keywords:}

Food analysis

Food composition

Wine color

Anthocyanins

UV-visible spectroscopy

Authenticity

Varietal classification

Vintage

Multivariate analysis

OPLS-DA

\begin{abstract}
A B S T R A C T
UV-visible spectra and color parameters of monovarietal wines with orthogonal partial least squarediscriminant analysis (OPLS-DA) were shown to be practical and rapid methods for classification purposes. Red and white wines from the 2006-2009 vintages were characterized in terms of color, anthocyanin content and UV-visible spectra. Syrah and Cabernet Sauvignon wines had high color density and intensity. Kalecik Karası wines had the highest CIELab parameters and the lowest color density. Boğazkere and Öküzgözü wines showed similarities with respect to their high red color parameters and were distinct from other wines. Merlot, Syrah and Öküzgözü wines had the highest total anthocyanin content $(61.9-55 \mathrm{mg} / \mathrm{L}$ as median values). White wines made from Chardonnay, Muscat and Emir grapes were found to have different color characteristics. The vintage-based discrimination of red wines was mostly apparent in total anthocyanin contents. Different UV wavelength regions were found to be effective in classification with respect to variety and vintage. Correct classification rates in the validation set were $100 \%$ and $75 \%$, for varietal and vintage classifications, respectively. This study demonstrated the potential of combination of UV-visible spectra and color characteristics to be used in the authentication of wines.
\end{abstract}

(c) 2015 Elsevier Inc. All rights reserved.

\section{Introduction}

The analysis of food by UV-visible spectroscopy is practical and environmentally friendly. In the wine industry and research, UVvisible spectroscopy is used for the definition of color. Evaluation of wine color through sensory analysis based on trained expert panelists is a common procedure for quality assessment. However, it can be time consuming, subjective and costly (Buratti et al., 2007; Rivas-Gonzalo et al., 1993). The International Organization of Vine and Wine (OIV) has recommended characterizing wine color using CIELab parameters, which are red/green $\left(a^{*}\right)$, yellow/ blue chromaticity $\left(b^{*}\right)$ and lightness $\left(L^{*}\right)$. The procedure is based on the transmittance measurements of wine samples between 380 and $780 \mathrm{~nm}$ and the calculation of chromatic characteristics and the derived parameters chroma $\left(C^{*}\right)$ and tone $\left(H^{*}\right)$ by using the information from several wavelengths. This analysis creates univariate color parameters from a multivariate spectral profile.

Wine color, as the first sensory attribute assessed by the consumers, gives an idea about the defects in wine, type of wine

\footnotetext{
* Corresponding author. Tel.: +90 232750 6295; fax: +90 2327506196 .

E-mail address: figentokatli@iyte.edu.tr (F. Tokatli).
}

and storage conditions, and it has an effect on the overall acceptability of wine (Pérez-Magariño and González-Sanjosé, 2003). The formation of color in grapes generally takes place during the veraison period with the biosynthesis of phenolic compounds (Ivanova et al., 2011; Kalkan Yildirim, 2006). In wine, color develops by the extraction of phenolic compounds in the grape during crushing, maceration and fermentation, and evolves through oxidation and aging (Gómez-Míguez et al., 2007; Ivanova et al., 2011). The color of young red wine comes from the small proportion of anthocyanins that is in the flavylium cation form and this form depends on $\mathrm{pH}$ and sulfur dioxide content of wine. Low $\mathrm{pH}$ enhances red color and color density, whereas increasing $\mathrm{pH}$ enhances blue color through decolorized anthocyanins. Sulfur dioxide has a reversible bleaching effect on anthocyanins (Jackson, 2000). During aging, polymerization and copigmentation of anthocyanins with tannins and other phenolic compounds take place and yield more stable pigments, which change wine color into brick-red. Wines with higher copigmentation and acylated form of non-malvidin compounds tend to have deeper color due to the capture of more pigments (Boulton, 2001; Heras-Roger et al., 2014). These numerous factors make evaluation of wine color an important and evolving research area. 
The assessment of wine authenticity ensures the standard quality of product since wine quality depends on several issues such as geographical origin, grape variety, climate, vintage and process conditions. Characterization and classification protects consumer from false labeling and fraudulent production (Jaitz et al., 2010; Versari et al., 2014). For this aim, quality labels such as Protected Designation of Origin (PDO) and Protected Geographical Indications (PGI) defined by the European Regulation (EEC) 2081/ 92 have been implemented. Wines can be characterized with respect to various chemical and physical parameters. After defining the product with its certain properties, it is possible to claim for the label, which definitely helps to gain high market value. So, it is important to evaluate wines with reliable and practical methods, both labor- and time-wise, for controlling bodies and companies. Spectrophotometric and chemometric methods can serve for this purpose.

The use of UV-visible spectra for wine classification was reported in some studies. Wines of two different varieties from different appellation d'origine were classified based on their UVvisible spectra by using principal component analysis (PCA) and Cooman's plots (Urbano et al., 2006). Geographical discrimination of Spanish wines was demonstrated by the use of UV-visible spectroscopy measurements along with support vector machines to select the relevant wavelengths (Acevedo et al., 2007). In some other studies, combined use of UV-visible range with near and mid infrared spectroscopy was shown to be effective in the classification, requiring more instrumentation other than a UV spectroscopy (Cozzolino et al., 2011). The color parameters accompanied with multivariate statistical methods have been employed in the characterization studies. In one study, rose, claret and blended wines were discriminated from each other according to their CIELab color parameters using neural network modeling and soft independent modeling of class analogy method (Meléndez et al., 2001). CIELab color coordinates were used to confirm the classification of white and rose wines by visual observation (Sáenz Gamasa et al., 2009). Strawberries of different cultivars were classified according to their CIELab color coordinates by linear discriminant analysis (Hernanz et al., 2008).

The aim of this study was to assess the effectiveness of using not only univariate color properties, $\mathrm{pH}$ and total anthocyanins, but also using multivariate information already collected over UV-visible range for color analysis, and to apply this information the characterization and classification of monovarietal wines. Unlike previous research, the combined data of color and UVvisible absorbance was used in multivariate models. Highlighting the differences between wines of indigenous types (Boğazkere, Öküzgözü, Kalecik Karası, and Emir) and wines of widely cultivated types (Cabernet Sauvignon, Merlot, Syrah, Chardonnay and Muscat) was another focus of this study. Multivariate statistical techniques such as principal component analysis (PCA) and orthogonal partial least squares-discriminant analysis (OPLS-DA) were employed for differentiation with respect to grape variety and vintage.

\section{Materials and methods}

\subsection{Wine samples}

The wine samples were selected from different geographical locations over 4 harvest years. The single-cultivar wines were purchased from local markets 2 years after their vintage. A total of 63 red and 28 white wine samples from vintages 2006-2009 were collected. The number of wine samples for each harvest year and the geographic origin is given in Table 1 . They were produced from 9 different commercially valuable grape varieties including Cabernet Sauvignon, Merlot, Syrah, Chardonnay, Muscat; and native varieties Boğazkere, Öküzgözü, Kalecik Karası and Emir. The samples were immediately analyzed for spectrometric and HPLC measurements after purchase.

\subsection{UV-visible spectroscopy and color analysis}

Spectrometric scans were collected according to the OIV method (2013) with a UV2450 model Shimadzu instrument (Shimadzu Inc., Kyoto, Japan). Transmittance scans between 400 and $700 \mathrm{~nm}$, with $2 \mathrm{~nm}$ sampling intervals were recorded with a quartz cuvette of $1 \mathrm{~mm}$ path length. The measurements were repeated three times. The CIELab colorimetric coordinates $\left(L^{*}, a^{*}, b^{*}\right)$ and their derivatives $\left(C^{*}\right.$ and $\left.H^{*}\right)$ were calculated by the Shimadzu UVPC color analysis software (ver. 2.7, Shimadzu Inc., Kyoto, Japan) using illuminant D65 and observer placed at $10^{\circ}$. The transmittance measurements taken by $1 \mathrm{~mm}$ path length cell were transformed to $10 \mathrm{~mm}$ before calculations. Other colorimetric parameters such as color density, color intensity, tint, proportion of red coloration and logarithmic color density were calculated by using absorbance values at $420 \mathrm{~nm}, 520 \mathrm{~nm}$ and $620 \mathrm{~nm}$.

\subsection{Total anthocyanin analysis by HPLC}

The anthocyanin content of red wine samples was determined and identified according to the method given in Sen and Tokatli (2014). Chromatographic analyses were performed on an Agilent 1200 series HPLC with a diode array detector at $520 \mathrm{~nm}$ (Agilent Technologies, Santa Clara, CA, USA). A C18 column $(5 \mu \mathrm{m}$, $250 \times 4.6 \mathrm{~mm}$ ) was used (AC Technologies, Aberdeen, Scotland). Wine samples were filtered through $0.45-\mu \mathrm{m}$ pore size membrane filters (Sartorius AG, Goettingen, Germany). Identification and quantification of anthocyanin-glycosides (malvidin3-O-glucoside, peonidin-3-O-glucoside, petunidin-3-O-glucoside, delphinidin-3-O-glucoside), their acetylated and coumaroylated derivatives (delphinidin-3-O-glucoside acetate, petunidin-3-O-glucoside acetate, peonidin-3-O-glucoside acetate, malvidin-3-O-glucoside acetate, delphinidin-3-O-glucoside

Table 1

The grape cultivar, harvest year, number of samples ${ }^{\mathrm{a}}$ and geographic origin of wines.

\begin{tabular}{|c|c|c|}
\hline Cultivar & Harvest years and number of samples & Geographic origin \\
\hline Boğazkere (Red) & $2006(1)-2007(2)-2008(3)-2009(2)$ & Diyarbakır, Cappadocia, Tokat \\
\hline Cabernet Sauvignon (Red) & $2006(2)-2007(5)-2008(1)$ & İzmir, Cappadocia, Thrace, Tokat, \\
\hline Kalecik Karası (Red) & $2006(5)-2007(6)-2008(3)$ & Ankara, Denizli, İzmir, Thrace \\
\hline Merlot (Red) & $2006(2)-2007(4)-2008(1)-2009(2)$ & Denizli, İzmir, Thrace \\
\hline Öküzgözü (Red) & $2006(3)-2007(3)-2008(2)-2009(3)$ & Elazığ, Cappadocia, Tokat \\
\hline Syrah (Red) & $2006(3)-2007(5)-2008(3)-2009(2)$ & Denizli, Manisa \\
\hline Emir (White) & $2007(3)-2008(3)-2009(3)$ & Cappadocia \\
\hline Chardonnay (White) & $2006(2)-2007(3)-2008(2)-2009(3)$ & Denizli, İzmir, Thrace, Cappadocia \\
\hline Muscat (White) & $2006(2)-2007(2)-2008(3)-2009(2)$ & Denizli, İzmir, Manisa \\
\hline
\end{tabular}

${ }^{\text {a }}$ Number of samples for each harvest year is given in parenthesis. 
Table 2

Color parameters and chemical results of wine samples. Number of samples are given in parenthesis.

\begin{tabular}{|c|c|c|c|c|c|c|c|c|c|c|c|c|c|c|c|c|}
\hline & & $\mathrm{pH}$ & $L^{*}$ & $a^{*}$ & $b^{*}$ & $C^{*}$ & $H^{*}$ & $\mathrm{CD}$ & $\mathrm{T}$ & $\mathrm{CI}$ & $\mathrm{dA}(\%)$ & $\mathrm{K}-\mathrm{K}$ & $\% \mathrm{R}$ & $\% \mathrm{Y}$ & $\% \mathrm{Bl}$ & $\begin{array}{l}\text { Tantho } \\
\text { (mg/L) }\end{array}$ \\
\hline \multirow[t]{3}{*}{ Boğazkere (8) } & Min & 3.31 & 20.3 & 50.5 & 32.1 & 60.1 & 31.1 & 5.17 & 0.58 & 5.73 & 70.8 & 0.71 & 50.6 & 33.0 & 8.95 & 10.5 \\
\hline & Max & 3.74 & 27.8 & 56.0 & 42.0 & 70.0 & 36.9 & 7.35 & 0.78 & 8.11 & 80.2 & 0.87 & 56.5 & 39.5 & 11.1 & 162 \\
\hline & Med & $3.46^{\mathrm{bc}}$ & $21.7^{\mathrm{bc}}$ & $54.4^{\mathrm{a}}$ & $34.4^{\mathrm{abc}}$ & $64.2^{\mathrm{abc}}$ & $33.0^{\mathrm{ab}}$ & $6,41^{\mathrm{bc}}$ & $0,71^{\mathrm{c}}$ & $7.12^{\mathrm{bc}}$ & $74.9^{\mathrm{a}}$ & $0.81^{\mathrm{b}}$ & $52.7^{\mathrm{a}}$ & $37.1^{\mathrm{b}}$ & $10.1^{\mathrm{ab}}$ & $40.8^{\mathrm{a}}$ \\
\hline \multirow{3}{*}{$\begin{array}{l}\text { Cabernet } \\
\text { Sauvignon (8) }\end{array}$} & Min & 3.51 & 5.71 & 31.4 & 9.82 & 32.9 & 17.4 & 4.35 & 0.83 & 4.86 & 52.2 & 0.64 & 40.4 & 39.4 & 10.1 & 1.53 \\
\hline & Max & 4.08 & 33.6 & 53.7 & 50.0 & 71.0 & 44.8 & 10.0 & 1.22 & 11.7 & 72.5 & 1.00 & 49.2 & 49.1 & 14.1 & 60.9 \\
\hline & Med & $3.73^{\mathrm{a}}$ & $18.3^{\mathrm{bc}}$ & $47.6^{\mathrm{b}}$ & $31.2^{\mathrm{bc}}$ & $56.9^{\mathrm{bc}}$ & $33.3^{\mathrm{ab}}$ & $7,60^{\mathrm{ab}}$ & $0,93^{\mathrm{a}}$ & $8.50^{\mathrm{ab}}$ & $65.6^{\mathrm{b}}$ & $0.88^{\mathrm{ab}}$ & $46.1^{\mathrm{e}}$ & $42.8^{\mathrm{a}}$ & $10.7^{\mathrm{a}}$ & $42.5^{\mathrm{a}}$ \\
\hline \multirow{3}{*}{$\begin{array}{l}\text { Kalecik } \\
\text { Karası (14) }\end{array}$} & Min & 3.33 & 23.7 & 49.2 & 28.8 & 60.8 & 27.1 & 3.25 & 0.76 & 3.55 & 57.4 & 0.51 & 44.1 & 38.9 & 8.22 & 12.8 \\
\hline & Max & 3.93 & 44.1 & 60.2 & 50.7 & 75.7 & 43.6 & 5.44 & 1.06 & 6.17 & 71.7 & 0.74 & 51.2 & 46.8 & 11.9 & 89.2 \\
\hline & Med & $3.71^{\mathrm{ab}}$ & $36.5^{\mathrm{a}}$ & $54.3^{\mathrm{a}}$ & $42.6^{a}$ & $69.2^{\mathrm{a}}$ & $38.9^{a}$ & $3.97^{c}$ & $0.92^{\mathrm{a}}$ & $4.37^{c}$ & $63.3^{\mathrm{b}}$ & $0.60^{c}$ & $47.4^{\text {de }}$ & $43.7^{\mathrm{a}}$ & $9.38^{\mathrm{b}}$ & $33.2^{\mathrm{a}}$ \\
\hline \multirow[t]{3}{*}{ Merlot (9) } & Min & 3.40 & 9.41 & 39.6 & 16.2 & 42.7 & 22.3 & 4.85 & 0.70 & 5.31 & 61.2 & 0.69 & 46.0 & 36.0 & 8.72 & 4.74 \\
\hline & Max & 3.85 & 33.0 & 55.0 & 51.6 & 75.4 & 43.1 & 10.6 & 0.97 & 12.1 & 77.4 & 1.02 & 51.2 & 44.8 & 12.9 & 102.2 \\
\hline & Med & $3.59^{\mathrm{abc}}$ & $20.4^{\mathrm{bc}}$ & $51.5^{\mathrm{ab}}$ & $34.5^{\mathrm{abc}}$ & $61.4^{\mathrm{abc}}$ & $34.7^{\mathrm{ab}}$ & $6.62^{\mathrm{ab}}$ & $0.80^{\mathrm{ab}}$ & $7.36^{\mathrm{ab}}$ & $70.3^{\mathrm{ab}}$ & $0.82^{\mathrm{ab}}$ & $49.8^{\mathrm{cd}}$ & $40.0^{\mathrm{ab}}$ & $11.0^{\mathrm{ab}}$ & $61.9^{a}$ \\
\hline \multirow[t]{3}{*}{ Öküzgözü (11) } & Min & 3.33 & 19.0 & 50.6 & 30.7 & 59.2 & 30.0 & 5.07 & 0.62 & 5.60 & 66.7 & 0.71 & 49.7 & 34.4 & 8.40 & 7.85 \\
\hline & Max & 3.70 & 30.8 & 58.3 & 48.3 & 75.7 & 39.6 & 6.91 & 0.84 & 7.76 & 78.8 & 0.84 & 55.8 & 41.7 & 11.5 & 120 \\
\hline & Med & $3.45^{c}$ & $23.9^{\mathrm{b}}$ & $54.8^{\mathrm{a}}$ & $36.5^{\mathrm{ab}}$ & $65.8^{\mathrm{ab}}$ & $34.8^{\mathrm{ab}}$ & $5.77^{\mathrm{bc}}$ & $0.73^{\mathrm{bc}}$ & $6.44^{\mathrm{bc}}$ & $73.4^{\mathrm{a}}$ & $0.76^{\mathrm{b}}$ & $51.6^{\mathrm{ab}}$ & $37.9^{\mathrm{b}}$ & $10.1^{\mathrm{ab}}$ & $55.0^{\mathrm{a}}$ \\
\hline \multirow[t]{3}{*}{ Syrah (13) } & Min & 3.49 & 3.23 & 22.5 & 5.57 & 23.2 & 13.9 & 5.83 & 0.69 & 6.47 & 63.4 & 0.77 & 45.6 & 34.9 & 9.86 & 21.7 \\
\hline & Max & 3.98 & 25.7 & 54.4 & 42.1 & 68.8 & 37.8 & 14.1 & 0.96 & 16.6 & 80.0 & 1.15 & 52.0 & 43.9 & 14.8 & 174 \\
\hline & Med & $3.65^{\mathrm{ab}}$ & $18.5^{\mathrm{c}}$ & $50.3^{b}$ & $31.3^{\mathrm{c}}$ & $59.2^{\mathrm{c}}$ & $31.8^{\mathrm{b}}$ & $7.73^{a}$ & $0.77^{\mathrm{bc}}$ & $8.63^{a}$ & $72,0^{\mathrm{a}}$ & $0.89^{a}$ & $50.3^{\mathrm{bc}}$ & $38.7^{\mathrm{b}}$ & $10.5^{\mathrm{a}}$ & $58.9^{\mathrm{a}}$ \\
\hline \multirow[t]{3}{*}{ Emir (9) } & Min & 2.97 & 96.8 & -1.40 & 4.13 & 4.18 & 92.8 & 0.08 & 3.51 & 0.08 & -174 & -1.11 & 14.0 & 71.9 & 2.70 & nd \\
\hline & Max & 3.95 & 99.1 & -0.46 & 10.2 & 10.2 & 101 & 0.21 & 5.80 & 0.23 & -56.9 & -0.67 & 20.6 & 81.4 & 7.63 & nd \\
\hline & Med & $3.21^{\mathrm{e}}$ & $98.6^{\mathrm{e}}$ & $-0.64^{\mathrm{e}}$ & $6.05^{\mathrm{ef}}$ & $6.09^{\mathrm{ef}}$ & $96.7^{\mathrm{f}}$ & $0.12^{\mathrm{ef}}$ & $4.68^{e}$ & $0.12^{\text {ef }}$ & $-126^{\mathrm{e}}$ & $-0.94^{\mathrm{e}}$ & $17.1^{\mathrm{e}}$ & $79.3^{\mathrm{e}}$ & $4.65^{\mathrm{e}}$ & nd \\
\hline \multirow[t]{3}{*}{ Chardonnay (10) } & Min & 3.03 & 97.0 & -1.41 & 5.25 & 5.36 & 95.0 & 0.09 & 3.99 & 0.09 & -253 & -1.05 & 12.0 & 74.3 & 1.67 & nd \\
\hline & Max & 3.62 & 99.2 & -0.93 & 10.7 & 10.7 & 102 & 0.20 & 7.21 & 0.22 & -80.4 & -0.69 & 18.6 & 86.4 & 7.09 & nd \\
\hline & Med & $3.44^{\mathrm{e}}$ & $98.6^{\mathrm{e}}$ & $-1.28^{f}$ & $8.17^{\mathrm{e}}$ & $8.27^{\mathrm{e}}$ & $99.5^{\mathrm{ef}}$ & $0.14^{\mathrm{e}}$ & $6.02^{\mathrm{e}}$ & $0.14^{\mathrm{e}}$ & $-170^{\mathrm{e}}$ & $-0.85^{\mathrm{e}}$ & $14.0^{\mathrm{ef}}$ & $84.0^{\mathrm{e}}$ & $2.16^{\mathrm{e}}$ & nd \\
\hline \multirow[t]{3}{*}{ Muscat (9) } & Min & 2.96 & 98.2 & -1.09 & 3.51 & 3.58 & 99.3 & 0.06 & 4.17 & 0.06 & -261 & -1.20 & 11.9 & 73.9 & 1.16 & nd \\
\hline & Max & 3.43 & 99.4 & -0.71 & 5.94 & 6.02 & 103 & 0.12 & 7.32 & 0.13 & -84.8 & -0.92 & 17.7 & 87.0 & 8.46 & nd \\
\hline & Med & $3.11^{\mathrm{e}}$ & $99.2^{\mathrm{e}}$ & $-0.89^{\mathrm{e}}$ & $4.77^{\mathrm{f}}$ & $4.87^{f}$ & $101^{\mathrm{e}}$ & $0.08^{f}$ & $5.65^{e}$ & $0.09^{f}$ & $-181^{\mathrm{e}}$ & $-1.08^{f}$ & $14.4^{\mathrm{f}}$ & $81.2^{\mathrm{e}}$ & $3.79^{\mathrm{e}}$ & nd \\
\hline
\end{tabular}

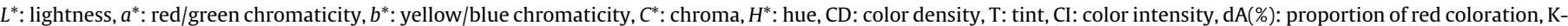
$\mathrm{K}$ : logarithmic color density, \%R: redness, \%Y: yellowness, \%Bl: blueness, min: minimum, max: maximum, med: median, nd: not detected.

Letters $\mathrm{a}, \mathrm{b}, \mathrm{c}$, $\mathrm{d}$ were used for the comparison of red wines. Letters e and $\mathrm{f}$ were used for the comparison of white wines.

Same letters in the columns indicate that the values are not different $(p>0.05)$.

HPLC method validation parameters for the determination of anthocyanins: recovery of red wines: $83 \pm 7 \%, \mathrm{LOD}: 0.03 \mathrm{mg} / \mathrm{L}$

coumarate, malvidin-3-O-glucoside coumarate) were performed according to calibration curve of malvidin-3-O-glucoside standard (Sigma Aldrich GmbH, Seelze, Germany). Duplicate measurements were performed. Total anthocyanin content values (Tantho) were given as the sum of all ten components given above. The method validation parameters are given in Table 2.

\subsection{Statistical analyses}

Principal component analysis (PCA) and orthogonal partial least square-discriminant analysis (OPLS-DA) were used to visualize the clusters of observations and evaluate the effect of grape variety and vintage on wine color properties. The OPLS-DA method explains the variation of data matrix $\mathbf{X}$ in three components: correlated/predictive variation $\left(\mathbf{t}_{\mathrm{p}}, \mathbf{p}_{\mathrm{p}}\right)$, uncorrelated/orthogonal variation $\left(\mathbf{t}_{\mathrm{o}}, \mathbf{p}_{\mathrm{o}}\right)$ and model residuals $(E)$, where $\mathbf{t}$ is the score matrix, $\mathbf{p}$ is the loading matrix:

$$
\mathbf{X}=\mathbf{t}_{\mathrm{p}} \mathbf{p}_{\mathrm{p}}+\mathbf{t}_{\mathrm{o}} \mathbf{p}_{\mathrm{o}}+E
$$

Orthogonal variation has been defined as "structured noise" or "irrelevant information" that exists in most experimental data and constitutes a larger proportion of information than those correlated to the response variables. The benefit of predictive and orthogonal variation is the extraction of most of the knowledge, which may lead to better performances than PLS models (Pinto et al., 2012). The number of components in OPLS-DA is given as " $\mathbf{p}_{\mathrm{p}}+\mathbf{p}_{\mathrm{o}}$ ". The significant variables that have the most impact on the OPLS-DA model were determined by the variable importance in the projection (VIP) plots created by Simca-P software (Eriksson et al., 2001). In discriminant analysis, a dummy $Y$ variable vector that symbolized the classes of wines was created (e.g. class 1 for Boğazkere wines, class 2 for Cabernet Sauvignon wines, etc.). The PCA and OPLS-DA models were defined with their number of principal components (PC), $R^{2}$ and $R_{\mathrm{pred}}^{2}$ as the coefficient of leave-one-out cross validation (LOO-CV). Approximately $18 \%$ of wine samples (eleven red wine and five white wines) were used as an independent set to validate the models. Validation results were reported as correct-classification rate (\%) for both LOO-CV and validation set. Confusion matrices of validations may be found in the online Supplementary Material (Tables S1-S4).

Red wines (63) and white wines (28) were analyzed separately. Two different data matrices were obtained from color measurements, HPLC analysis and UV-visible spectroscopy. Data of color parameters, $\mathrm{pH}$ and total anthocyanins were arranged in $(N \times K)$ matrices, where $N$ was the number of observations and $K$ was the number of color parameters, $\mathrm{pH}$ and total anthocyanins (no anthocyanin data for white wines). Data of UV-visible absorbance were arranged as $(N \times M)$ matrices, where $M$ was the number of wavelengths. PCA models were built to realize the similarities/ differences of wines with respect to their color characteristics and anthocyanin contents. UV-visible spectra combined with color, $\mathrm{pH}$ and total anthocyanins of wine samples were used to build OPLSDA models for varietal and vintage classification. Preprocessing of spectra improved the model performance as opposed to raw UV-visible data. Prior to modeling, spectra were filtered by taking the first and second order derivative for varietal and vintage classification, respectively. Taking the derivative of data is widely 
applied to eliminate scatter effects. In the spectral data, the first and second derivative is used to remove baseline shifts and drifts (Casale et al., 2010). Simca-P statistical software (ver. 13.0.3; Umetrics Inc., Umea, Sweden) was used for multivariate analysis.

\section{Results and discussion}

\subsection{Principal component analysis (PCA)}

Grape varieties like Cabernet Sauvignon, Merlot, Syrah, Muscat and Chardonnay are cultivated widely in wine producing regions along with the native grapes of those particular parts of country. Turkey is the fifth largest country in grape production. It has diversity in its microbiological flora and has many grape varieties for wine production (Gumus and Gumus, 2008). There are also indigenous grape varieties used for wine production, such as Boğazkere, Öküzgözü, Kalecik Karası and Emir.

PCA as an unsupervised statistical technique was used to reveal color characteristics of the monovarietal wine samples. A PCA model with two principal components, $R^{2}$ of 0.84 and $R_{\text {pred }}^{2}$ of 0.76 , was built with color parameters, $\mathrm{pH}$ and total anthocyanins. The clusters of red wines from different cultivars and effect of variables in the formation of the groupings can be observed in Fig. $1 \mathrm{a}$ and $\mathrm{b}$ (score and loading plots). Syrah and Kalecik Karası wines appeared on the opposite sides of the first principal component although majority of Syrah and Kalecik Karası wines were from the same geographical origin (Denizli region in western Anatolia). Kalecik Karası wines had the highest CIELab parameters and lowest color density, color intensity and logarithmic color density. The color density and the tint values of Kalecik Karası wines were similar to Monastrell wines from Spain (Gomez-Plaza et al., 1999). Cabernet Sauvignon and Syrah wines had significantly the highest blueness and the lowest lightness. Moreover, Syrah wines had the highest color density, color intensity and logarithmic color density, which were followed by Cabernet Sauvignon wines. These two varieties, at the same time, had the lowest CIELab color parameters. The chroma and blueness of Cabernet Sauvignon wines were similar to the wines of Argentina (Fanzone et al., 2012). High color intensity of Cabernet Sauvignon wines of Argentina was related to their high blueness and redness, respectively. According to another study about the phenolic profiles of red wines, Syrah wines were found significantly rich in flavonol and anthocyanin compounds (Sen and Tokatli, 2014). The high color density, color intensity, logarithmic color density and low lightness values of Syrah wines might be due to their rich anthocyanin and flavonol contents. It was reported that the wines rich in anthocyanin and total phenol contents tend to have higher color intensity, chroma, red/green chromaticity, yellow/blue chromaticity and lower lightness (Fanzone et al., 2012; Ivanova-Petropulos et al., 2015). No particular color characteristics were found significant for Merlot wines. The redness, yellowness, blueness and color intensity of Merlot wines were in good agreement with those from southern Spain, while Syrah wines had higher color intensity and redness and lower yellowness than Syrah wines of southern Spain (Marquez et al., 2014). The second PC discriminated Boğazkere and Öküzgözü wines from Cabernet Sauvignon wines. Boğazkere and Öküzgözü wines had higher redness, red/green chromaticity, chroma and proportion of red coloration values. Boğazkere, Öküzgözü and Syrah wines had significantly higher redness and lower yellowness than other varieties. The high proportion of red coloration values of Boğazkere and Öküzgözü wines might be related to their lower $\mathrm{pH}$ that enhances red color and color density (Jackson, 2000). These wines showed some similarity to Malbec wines of Argentina in terms of lightness, red/green chromaticity, redness and yellowness (Fanzone et al., 2012). The correlation coefficients $(r)$ between color parameters revealed that tint and yellowness were negatively correlated $(r=-0.47$ and $r=-0.49)$, while redness and proportion of red coloration was positively correlated $(r=0.48$ and $r=0.46)$ to the total anthocyanin values. Based on the phenolic data of our wine samples given elsewhere (Sen and
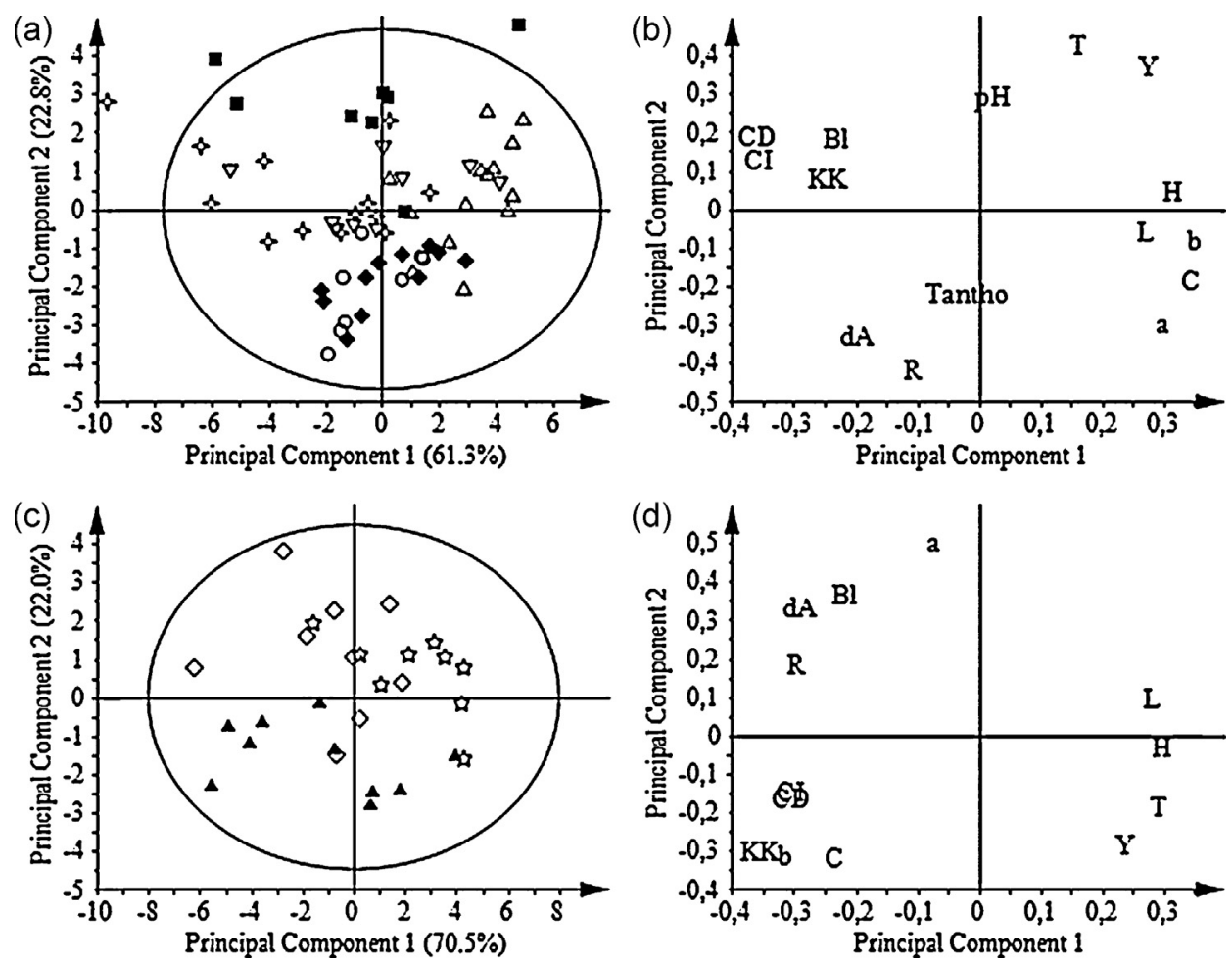

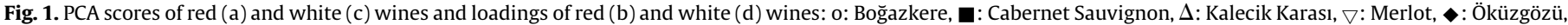

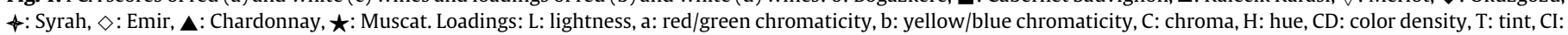
color intensity, dA: proportion of red coloration, KK: logarithmic color density, R: redness, Y: yellowness, Bl: blueness, Tantho: total anthocyanins. 
Tokatli, 2014), it was observed that tint and yellowness were negatively correlated, redness was positively correlated to the petunidin-3-glucoside and delphinidin-3-glucoside compounds $(r=-0.49$ and $r=0.59$, respectively). Kalecik Karası and Cabernet Sauvignon had low redness, and high tint and yellowness values. PCA model built with color parameters of white wines had four components and $R^{2}$ of 0.99 and $R_{\text {pred }}^{2}$ of 0.97 . Chardonnay wines were separated from Emir and Muscat wines with their high yellow/blue chromaticity, chroma values and the lowest red/green chromaticity (Fig. 1c and d). Muscat wines, on the other hand, had the highest lightness and the lowest yellow/blue chromaticity values. Emir wines were not significantly high in any color parameters.

\subsection{Orthogonal partial least square-discriminant analysis (OPLS-DA)}

OPLS-DA models were tested with two different data sets for varietal and vintage discrimination of wine samples. The first data set included color variables, $\mathrm{pH}$ and total anthocyanin contents. The second data set included the first-order derivative of UVvisible spectra besides the color data (the first set). For comparison, the results of the models were given in terms of components, model fits and prediction abilities (Table 3). PLS-DA models were also tried. However, the discrimination ability was not equal to that of OPLS-DA models. Score plots were given only for OPLS-DA models, which were built with combined data of UV-visible absorbance, color, pH and total anthocyanins (Figs. 2 and 3).

\subsubsection{Varietal discrimination by OPLS-DA}

In the varietal discrimination, wines of different cultivars were grouped in separate classes. Based on the PCA results of red wines (Fig. 1a), Boğazkere and Öküzgözü were considered as one class since they were the most similar in terms of their color characteristics. As seen in Table 3 and score plots (Fig. 2a), OPLS-DA model with color and the first-order derivative of UVvisible data separated the red wines. It was observed that use of UV-visible spectra along with color parameters could reveal more information and improve classification. For comparison purpose, PLS-DA model with the same data was also built (six components produced $R^{2}$ of 0.56 and $R_{\text {pred }}^{2}$ of 0.39 ). Even though model performances of OPLS-DA and PLS-DA seemed very similar, the inclass variation in PLS-DA was higher and some outliers were observed (scatter plot was not shown). The score plot of OPLS-DA model shows the separation of wines from indigenous varieties of Anatolia from Cabernet Sauvignon, Merlot and Syrah wines. With respect to the first principal component, Kalecik Karası wines were separated from other samples, especially Syrah due to their differences in lightness, color density and color intensity. Similarly, according to the second principal component, Cabernet Sauvignon and Syrah wines were separated from Boğazkere-Öküzgözü class, due to the lower $\mathrm{pH}$ and higher red/green chromaticity values of the latter. Merlot wines were found closer to Cabernet Sauvignon and Syrah rather than indigenous varieties. Total anthocyanin contents of wines did not show significant differences, however, Merlot, Syrah and Öküzgözü wines were found to have higher

Table 3

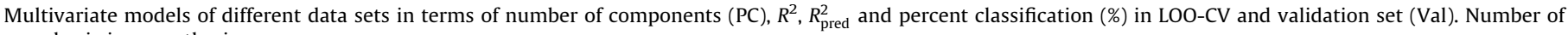
samples is in parenthesis.

\begin{tabular}{|c|c|c|c|c|c|c|}
\hline & \multicolumn{3}{|l|}{ Varietal discrimination } & \multicolumn{3}{|l|}{ Vintage discrimination } \\
\hline & \multirow{2}{*}{$\begin{array}{l}\text { Color data }+\mathrm{pH}+\text { Tantho } \\
\text { OPLS-DA }\end{array}$} & \multicolumn{2}{|c|}{$\begin{array}{l}\text { UV-visible + color } \\
\text { data }+\mathrm{pH}+\text { Tantho }\end{array}$} & \multirow{2}{*}{$\begin{array}{l}\text { Color data }+\mathrm{pH}+\text { Tantho } \\
\text { OPLS-DA }\end{array}$} & \multicolumn{2}{|c|}{$\begin{array}{l}\text { UV-visible + color } \\
\text { data + pH + Tantho }\end{array}$} \\
\hline & & PLS-DA & OPLS-DA & & PLS-DA & OPLS-DA \\
\hline \multicolumn{7}{|l|}{ Red } \\
\hline PC & $2+1$ & 6 & $4+1$ & $3+0$ & 1 & $2+2$ \\
\hline$R^{2}$ & 0.33 & 0.56 & 0.54 & 0.35 & 0.17 & 0.40 \\
\hline$R_{\text {pred }}^{2}$ & 0.27 & 0.39 & 0.39 & 0.29 & 0.15 & 0.22 \\
\hline LOO-CV $(N=52)$ & 67 & 86 & 83 & 71 & 53 & 71 \\
\hline Val $(N=11)$ & 90 & 100 & 100 & 45 & 36 & 73 \\
\hline \multicolumn{7}{|l|}{ White } \\
\hline PC & $2+1$ & 3 & $2+1$ & $1+2$ & 1 & $2+1$ \\
\hline$R^{2}$ & 0.65 & 0.74 & 0.74 & 0.31 & 0.26 & 0.52 \\
\hline$R_{\text {pred }}^{2}$ & 0.55 & 0.61 & 0.59 & 0.14 & 0.12 & 0.33 \\
\hline LOO-CV $(N=23)$ & 91 & 96 & 96 & 62 & 54 & 79 \\
\hline Val $(N=5)$ & 100 & 100 & 100 & 50 & 50 & 75 \\
\hline
\end{tabular}

(a)

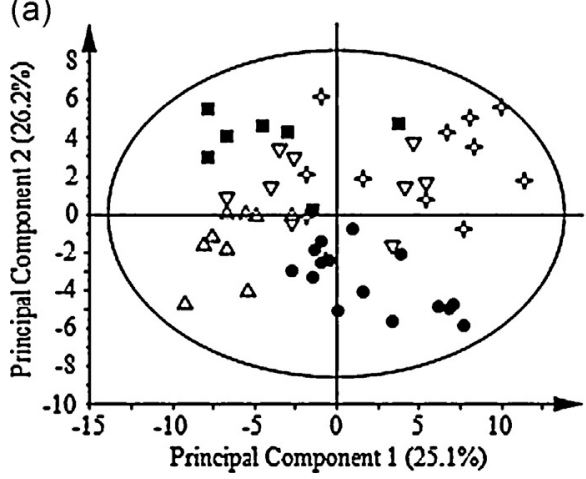

(b)

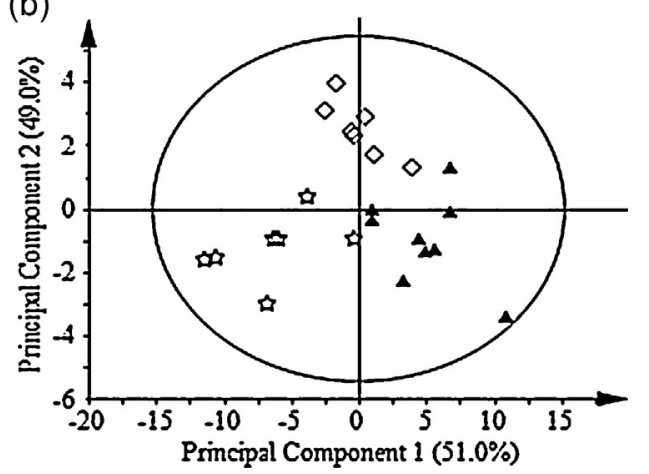

Fig. 2. Varietal discrimination of red (a) and white (b) wines: Score plots of OPLS-DA models. Syrah, $\diamond$ : Emir, $\boldsymbol{\Delta}$ : Chardonnay, $\star$ : Muscat. 
(a)

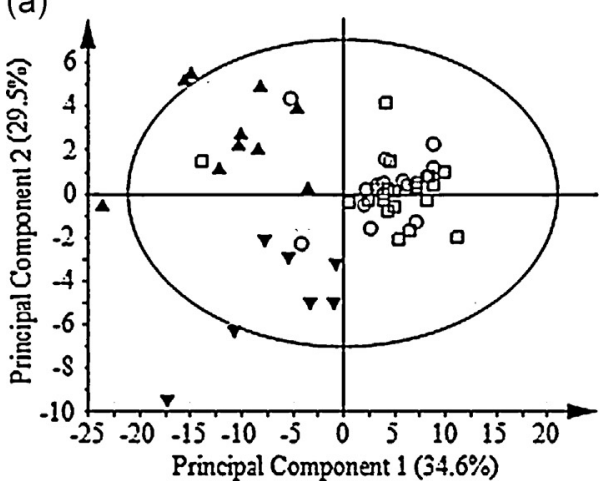

(b)

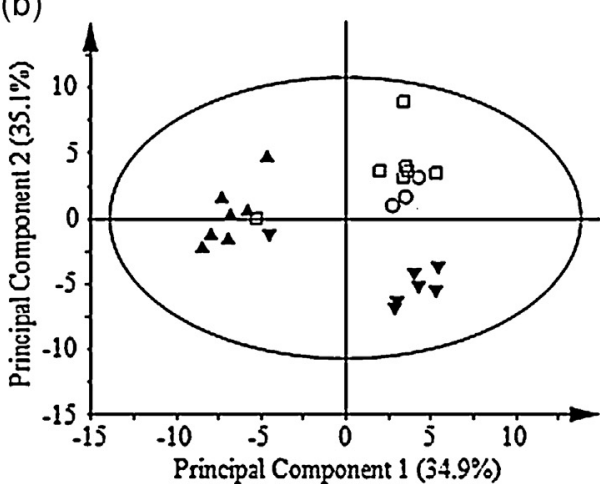

Fig. 3. Vintage discrimination of red (a) and white (b) wines: Score plots of OPLS-DA models. o: 2006, $\square: 2007, \boldsymbol{\Delta}: 2008, \boldsymbol{\nabla}: 2009$.

anthocyanin content in terms of median values (Table 2). According to variable importance calculations of OPLS-DA model, the most effective parameters were lightness, redness, logarithmic color density, color density and color intensity. In the UV-visible spectra, regions between $414-458 \mathrm{~nm}$ and $514-538 \mathrm{~nm}$ were observed as the most influential in the classification red wines.

In the varietal classification of white wines, using only color parameters did not produce a satisfactory separation among wines. The OPLS-DA model with the combined data of color characteristics and UV-visible absorbances could discriminate three white wines with $R^{2}$ of 0.74 and $R_{\text {pred }}^{2}$ of 0.59 . In the score plot, all three white wines were positioned in different parts of the control ellipse (Fig. 2b). VIP of the OPLS-DA model showed that the most significant color parameters in the separation were redness, tint, red coloration, hue, red/green chromaticity, yellowness and blueness. Wavelengths between $464-490 \mathrm{~nm}$ and $670-686 \mathrm{~nm}$ were found as the most influential ranges for varietal separation of white wines.

\subsection{Vintage discrimination by OPLS-DA}

The models were created with two data sets: data of color, $\mathrm{pH}$ and total anthocyanins and the combined data of analytics and UV-visible spectra. In the discrimination with respect to vintage, the second-order derivative of UV-visible spectra gave the best separation. It was observed that red wines of 2008 and 2009 were different than those of 2006 and 2007 (Fig. 3a). The CIELab colorimetric parameters (red/green chromaticity, chroma and hue), yellowness, and tint values were lower while proportion of red coloration and redness values were higher for 2008-2009 vintage wines. The wines of 2009 vintage had higher anthocyanin content than the rest (Sen and Tokatli, 2014). Total anthocyanin content with a VIP value of 2.4 was the most influential variable for characterizing wines with respect to vintage. As reported elsewhere, anthocyanins and their polymerization degree were found to be directly related to wine color density and they were effective in the differentiation of wines according to their harvest year (Rivas-Gonzalo et al., 1993). Other parameter with influence on vintage classification was $\mathrm{pH}$. The regions between $490-500 \mathrm{~nm}$ and $586-600 \mathrm{~nm}$ were observed as the most effective in the discrimination of red wines with respect to vintage. In case of white wines, wines of 2008 were different than others wines (Fig. 3b). The most significant color parameters in the separation of white wines with respect to vintage were hue, red/green chromaticity, blueness, redness, tint, red coloration and yellowness. The wavelengths between $490-514 \mathrm{~nm}$ and $562-684 \mathrm{~nm}$ were found as the most important variables.

In the validation of classification models, the percent correct classification (\%) for LOO-CV (internal validation) and the validation set (Val) were given in Table 3. The combined data of UV and chemical parameters (color, $\mathrm{pH}$ and total anthocyanins) predicted the varietal class of new samples equally good or better than the data of chemical parameters. The OPLS-DA models of combined data performed better for the discrimination with respect to vintage. The number of samples and correct classification rates in each class are presented in confusion tables, which may be found in the online Supplementary Material (Tables S1-S4).

The potential of the proposed methodology for the discrimination of wines was tested with respect to two factors, grape variety and vintage. The classifications were satisfactory despite the possible variations in the processing stages of wines. The parameters affecting the wine color and anthocyanins such as winemaking and storage practices can also be studied with controlled wine samples. The significance of this work is the evaluation of information obtained with easy-toacquire data. Results of the study might serve as a good base for authentication of wine samples and other food products with the combination of different analytical data and UV-visible spectra.

\section{Conclusion}

UV-visible spectra and color characteristics were shown to be effective in the discrimination of wines as a simple, uncomplicated and rapid method. The first and second derivative processes of UV absorbance improved the separation of wines from different grape types and harvest year. OPLS-DA models built by the spectral and color data were also able to separate wines produced from native and non-native grapes grown in Turkey. The models were effective to differentiate red wines of 2006-2007 from those of 2008 and 2009 based on the total anthocyanin contents. White wines of 2008 harvest showed significant differences from the other wines. This procedure can be further applied in the discrimination and authentication of other food materials such as fruit juices and olive oils.

\section{Acknowledgement}

This research was financially supported by Izmir Institute of Technology (Scientific Research Projects: 2008IYTE18 and 2010IYTE07)

\section{Appendix A. Supplementary data}

Supplementary data associated with this article can be found, in the online version, at http://dx.doi.org/10.1016/j.jfca.2015.09.018. 


\section{References}

Acevedo, F.J., Jimenez, J., Maldonado, S., Dominguez, E., Narvaez, A., 2007. Classification of wines produced in specific regions by UV-visible spectroscopy combined with support vector machines. J. Agric. Food Chem. 55, 6842-6849.

Boulton, R., 2001. The copigmentation of anthocyanins and its role in the color of red wine: a critical review. Am. J. Enol. Vitic. 52 (2), 67-87.

Buratti, S., Ballabio, D., Benedetti, S., Cosio, M.S., 2007. Prediction of Italian red wine sensorial descriptors from electronic nose, electronic tongue and spectrophotometric measurements by means of Genetic Algorithm regression models. Food Chem. 100 (1), 211-218.

Casale, M., Oliveri, P., Armanino, C., Lanteri, S., Forina, M., 2010. NIR and UV-vis spectroscopy, artificial nose and tongue: comparison of four fingerprinting techniques for the characterisation of Italian red wines. Anal. Chim. Acta 668 (2), 143-148.

Cozzolino, D., Cynkar, W.U., Shah, N., Smith, P.A., 2011. Can spectroscopy geographically classify Sauvignon Blanc wines from Australia and New Zealand? Food Chem. 126 (2), 673-678.

Eriksson, L., Johanson, E., Wold, N.K., Wold, S., 2001. Multi- and Megavariate Data Analysis: Principles and Applications. Umetrics AB, Umea, Sweden.

Fanzone, M., Pena-Neira, A., Gil, M., Jofre, V., Assof, M., Zamora, F., 2012. Impact of phenolic and polysaccharidic composition on commercial value of Argentinean Malbec and Cabernet Sauvignon wines. Food Res. Int. 45 (1), $402-414$.

Gómez-Míguez, M.J., Gómez-Míguez, M., Vicario, I.M., Heredia, F.J., 2007. Assessment of colour and aroma in white wines vinifications: effects of grape maturity and soil type. J. Food Eng. 79 (3), 758-764.

Gomez-Plaza, E., Munoz, R.G., Roca, J.M.L., Martinez, A., 1999. Color and phenolic compounds of a young red wine as discriminating variables of its ageing status. Food Res. Int. 32, 503-507.

Gumus, S.G., Gumus, A.H., 2008. The wine sector in Turkey: survey on 42 wineries. Bulg. J. Agric. Sci. 14 (6), 549-556.

Heras-Roger, J., Pomposo-Medina, M., Díaz-Romero, C., Darias-Martín, J., 2014. Copigmentation, colour and antioxidant activity of single-cultivar red wines. Eur. Food Res. Technol. 239 (1), 13-19.

Hernanz, D., Recamales, A.F., Melendez-Martinez, A.J., Gonzalez-Miret, M.L., Heredia, F.J., 2008. Multivariate statistical analysis of the color-anthocyanin relationships in different soilless-grown strawberry genotypes. J. Agric. Food Chem. 56, 2735-2741.

Ivanova-Petropulos, V., Hermosín-Gutiérrez, I., Boros, B., Stefova, M., Stafilov, T., Vojnoski, B., Dörnyei, Á., Kilár, F., 2015. Phenolic compounds and antioxidant activity of Macedonian red wines. J. Food Compos. Anal. 41, 1-14.
Ivanova, V., Stefova, M., Vojnoski, B., Dörnyei, Á., Márk, L., Dimovska, V., Stafilov, T., Kilár, F., 2011. Identification of polyphenolic compounds in red and white grape varieties grown in R. Macedonia and changes of their content during ripening. Food Res. Int. 44 (9), 2851-2860.

Jackson, R.S., 2000. Wine Science Principles, Practice, Perception, second ed. Academic Press, San Diego, CA, USA

Jaitz, L., Siegl, K., Eder, R., Rak, G., Abranko, L., Koellensperger, G., Hann, S., 2010. LC-MS/MS analysis of phenols for classification of red wine according to geographic origin, grape variety and vintage. Food Chem. 122 (1), 366-372.

Kalkan Yildirim, H., 2006. Evaluation of colour parameters and antioxidant activities of fruit wines. Int. J. Food Sci. Nutr. 57 (1-2), 47-63.

Marquez, A., Serratosa, M.P., Merida, J., 2014. Influence of bottle storage time on colour, phenolic composition and sensory properties of sweet red wines. Food Chem. 146, 507-514.

Meléndez, M.E., Sánchez, M.S., Íñiguez, M., Sarabia, L.A., Ortiz, M.C., 2001. Psychophysical parameters of colour and the chemometric characterisation of wines of the certified denomination of origin 'Rioja'. Anal. Chim. Acta 446, $159-169$.

OIV, 2013. Compendium of International Methods of Wine and Must Analysis, vol. 1. International Organisation of Vine and Wine.

Pérez-Magariño, S., González-Sanjosé, M.L., 2003. Application of absorbance values used in wineries for estimating CIELAB parameters in red wines. Food Chem. 81 (2), 301-306.

Pinto, R.C., Trygg, J., Gottfries, J., 2012. Advantages of orthogonal inspection in chemometrics. J. Chemom. 26 (6), 231-235.

Rivas-Gonzalo, J.C., Gutierrez, Y., Polanco, A.M., Hebrero, E., Vicente, J.L., Galindo, P., Santos-Buelga, C., 1993. Biplot analysis applied to enological parameters in the geographical classification of young red wines. Am. J. Enol. Vitic. 44 (3), 302-308.

Sáenz Gamasa, C., Hernández, B., Santiago, J.V., Alberdi, C., Alfonso, S., Diñeiro J.M., 2009. Measurement of the colour of white and rosé wines in visual tasting conditions. Eur. Food Res. Technol. 229 (2), 263-276.

Sen, I., Tokatli, F., 2014. Authenticity of wines made with economically important grape varieties grown in Anatolia by their phenolic profiles. Food Control 46, 446-454.

Urbano, M., Luque de Castro, M.D., Pérez, P.M., García-Olmo, J., Gómez-Nieto, M.A., 2006. Ultraviolet-visible spectroscopy and pattern recognition methods for differentiation and classification of wines. Food Chem. 97 (1) $166-175$.

Versari, A., Laurie, V.F., Ricci, A., Laghi, L., Parpinello, G.P., 2014. Progress in authentication, typification and traceability of grapes and wines by chemometric approaches. Food Res. Int. 60, 2-18. 